\title{
Anaphylaxis to a self-peptide in the absence of mast cells or histamine
}

\author{
Silvia Musio ${ }^{1}$, Paola Pedotti ${ }^{2}$, Renato Mantegazza ${ }^{1}$, Hiroshi Ohtsu ${ }^{3}$, Louis Boon ${ }^{4}$, Lawrence Steinman ${ }^{5,6}$, \\ Stephen J Galli ${ }^{7,8}$ and Rosetta Pedotti ${ }^{1}$
}

Induction of T helper 1 (Th1) to Th2 deviation through administration of self- or altered self-peptides holds promise for treatment of autoimmunity. However, administration of self-peptides in models of autoimmunity can result in anaphylactic reactions. Although both $\lg E$ and $\lg G 1$ antibodies might be involved in the development of anaphylaxis to myelin peptides in experimental autoimmune encephalomyelitis in mice, the effector cells and molecules involved are not fully understood. Here we show that systemic anaphylaxis to the self-antigen myelin oligodendrocyte glycoprotein (MOG) 35-55 can occur in mice lacking mast cells ( $\mathrm{Kit}^{W} / \mathrm{Kit}^{\mathrm{W}-\mathrm{v}}$ mice) or histamine (histidine decarboxylase-deficient mice), but is prevented in mice lacking IL-4. Treatment of mice with CV6209, a platelet-activating factor antagonist, slightly reduced the incidence of anaphylaxis to self-MOG35-55 in this model, but more effectively protected mice against anaphylaxis to this peptide when self-MOG35-55 was administered in a different immunization protocol that omitted the use of Bordetella pertussis toxin as an adjuvant at the time of immunization. Thus, anaphylactic reactions to self-MOG can occur in the absence of mast cells or histamine, key elements of the classical lgE-, mast cell-, and histamine-dependent pathway of anaphylaxis.

Laboratory Investigation (2009) 89, 398-405; doi:10.1038/labinvest.2009.4; published online 2 February 2009

KEYWORDS: anaphylaxis; experimental autoimmune encephalomyelitis; histamine; IL-4; mast cells; self-peptide

Multiple sclerosis (MS) and its animal model, experimental autoimmune encephalomyelitis (EAE), are immunemediated diseases of the central nervous system in which $\mathrm{T}$ helper 1 (Th1) $\mathrm{CD}^{+}{ }^{+}$cells reacting to myelin are considered to have a leading role. ${ }^{1}$ Therapeutic approaches aimed to shift the immune response against myelin antigens from Th1 to Th2 by i.v. injection(s) of soluble myelin peptides or proteins have been shown to induce antigen-specific immune tolerance and amelioration of EAE (reviewed in Fontoura et $a l^{2}$ ). However, such therapeutic approaches have substantial potential risk. ${ }^{3}$ Mice with EAE can develop fatal anaphylaxis on re-exposure to certain self-peptides of the myelin sheath. ${ }^{4-8}$ Repeated administration of self- or altered self-peptides resulted in immediate hypersensitivity reactions in a subset of patients with MS treated with NB5788, an altered peptide ligand (APL) of myelin basic protein, ${ }^{9}$ and in
9\% of MS patients treated with glatiramer acetate, a random four-amino-acid non-self-polymer widely used for the treatment of this disease. ${ }^{10}$

Anaphylaxis in humans is thought to be mediated largely (if not solely) by a pathway consisting of IgE antibodies, the high-affinity receptor for IgE (FceRI), mast cells and basophils, and histamine is thought to represent a major mediator of such anaphylactic reactions (reviewed in Kawakami et $a l^{11}$ ). However, in mice, anaphylaxis can be elicited either by IgE- or by IgG1-dependent mechanisms. ${ }^{12}$ The second, IgG1-dependent, pathway is IgE-independent, but requires the low-affinity receptor for IgG (Fc $\gamma$ RIII) and, depending on the setting, can involve basophils and perhaps macrophages, and platelet-activating factor (PAF). ${ }^{12-15}$ In a chronic EAE model, induced in C57BL/6 mice by immunization with the self-myelin peptide oligodendrocyte glycoprotein (MOG)

${ }^{1}$ Immunology and Muscular Pathology Unit, Neurological Institute Foundation IRCCS Carlo Besta, Milan, Italy; ${ }^{2}$ Institute of Medical and Biomedical Statistics 'Giulio A. Maccacaro' University of Milan, Milan, Italy; ${ }^{3}$ Department of Applied Quantum Medical Science, Tohoku University School of Engineering, Sendai, Japan; ${ }^{4}$ Bioceros, Utrecht, The Netherlands; ${ }^{5}$ Department of Neurology and Neurological Sciences, Stanford University, Stanford, CA, USA; ${ }^{6}$ Interdepartmental Program in Immunology,

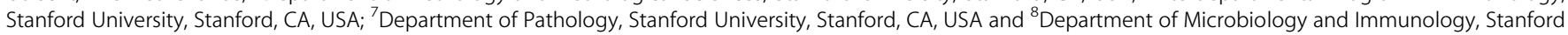
University, Stanford, CA, USA

Correspondence: Dr R Pedotti, MD, PhD, Immunology and Muscular Pathology Unit, Neurological Institute Foundation IRCCS Carlo Besta, Via Celoria 11, Milan 21033, Italy.

E-mail: rpedotti@istituto-besta.it

Received 19 September 2008; revised 28 November 2008; accepted 22 December 2008 
35-55, we and others found that anaphylaxis to self was abrogated in mice lacking the $\gamma$-chain common to $\mathrm{Fc}$ receptors $(\mathrm{FcR}),{ }^{5,8}$ but not in mice lacking the $\alpha$ chain of Fc $\gamma$ RIII (Fc $\gamma$ RIII $\alpha$ chain $\left.^{-1-}\right)$, suggesting that the IgE-Fc $\varepsilon$ RImast cell/basophil-histamine pathway might contribute to the development of anaphylaxis in this model. ${ }^{5,8}$ However, except for the findings obtained in various FcR-knockout mice, the effector cells and molecules involved in anaphylaxis to this self-myelin peptide are not fully understood. A better understanding of the mechanisms contributing to such reactions may help in the development of strategies aimed at preventing and/or treating undesired allergic reactions associated with peptide therapies for autoimmune disorders. We therefore analyzed the importance of mast cells, histamine and IL-4, key elements of IgE-dependent anaphylaxis, in the development of anaphylaxis to self-MOG35-55 in a chronic model of EAE. We also attempted to prevent anaphylaxis to this self-peptide by using CV6209, an antagonist of PAF, a key mediator in the development of IgG1-dependent anaphylaxis. Here we show that anaphylaxis to self-MOG35-55 requires neither mast cells nor histamine, but it does require IL-4. Our results also suggest that PAF can contribute to the development of anaphylaxis to this selfpeptide, but PAF probably is not the only mediator involved.

\section{MATERIALS AND METHODS Mice}

Eight- to twelve-week-old mast cell-deficient $\mathrm{WBB} \mathrm{F}_{1}-\mathrm{Kit}^{\mathrm{W} / \mathrm{Wv}}$ $\left(W / W^{\nu}\right)$ and congenic wild-type $\left(\mathrm{WBB} \mathrm{F}_{1}-\mathrm{Kit}^{+/+}\right)$female mice (Jackson Laboratory, ME, USA), C57BL/6J-IL- $4^{-1-}$ and wild-type C57BL/6J mice (Jackson Laboratory), histidine decarboxylase-deficient mice $\left(\mathrm{HDC}^{-1-}\right)$ backcrossed six generations onto C57BL/6 (provided by Dr H Ohtsu, Sendai, Japan $)^{16}$ and wild-type C57BL/6N (Charles-Rivers, Calco, Italy) were used in this study. Experiments were conducted in the animal facilities of the Neurological Institute Foundation Carlo Besta or of Stanford University. All procedures involving animals were approved by the ethical committee of the Neurological Institute Foundation Carlo Besta and the Division of Comparative Medicine at Stanford University, and carried out according to the Principles of Laboratory Animal Care (European Communities Council Directive 86/609/EEC) and the National Institutes of Health guidelines.

\section{Peptides}

MOG35-55 (MEVGWYRSPFSRVVHLYRNGK), control peptide-1 (random-CAVPLKTQMSGSSFM), and control peptide-2 (acetylcholine receptor, AchR, 97-116; DGDFAIVKFTKVLLDYTGHI) were synthesized and purified to $>95 \%$ by analytical reverse-phase HPLC.

\section{Immunization Protocol}

EAE was induced as described earlier ${ }^{5}$ by subcutaneous immunization with MOG35-55 (100 $\mu \mathrm{g}$ per mouse) in Complete Freund's Adjuvant (CFA; Difco Laboratories,
Detroit, MI, USA), containing $4 \mathrm{mg} / \mathrm{ml}$ of heat-killed Mycobacterium tuberculosis H37Ra (Difco Laboratories). All mice also received two intravenous injections of Bordetella pertussis (B. pertussis) toxin (200 ng/mouse) (List Biological Laboratories, Campbell, CA, USA) on day 0 and day 2 post immunization. The clinical features of EAE, which developed in all of the mice used in this study, have already been described. $^{6,17-19}$ In another model of MOG35-55-induced EAE, mice were immunized without using $B$. pertussis toxin as an adjuvant (see Results section for details).

\section{Induction of Active Systemic Anaphylaxis}

We evaluated whether mice exhibited active systemic anaphylaxis by challenging them 6 weeks after induction of EAE with an i.p. injection of MOG35-55 (100 $\mu \mathrm{g})$ dissolved in PBS $(100 \mu \mathrm{l})$. Control mice were challenged with an i.p. injection of a control peptide at the same dose. Mice were observed for $1 \mathrm{~h}$ after peptide challenge for clinical signs of anaphylaxis, and for each mouse body temperature was recorded with a rectal probe (Physitemp Instruments, Clifton, NJ, USA) at baseline and at 5, 10, 20, 30, and $60 \mathrm{~min}$ after challenge. ${ }^{5}$ Data are shown as mean \pm s.e.m. for all mice in each group. In the groups in which some mice died during the observation period of $1 \mathrm{~h}$, mean values were determined on the basis of data for the surviving mice. Mice were considered to have anaphylaxis when suggestive clinical signs (ie, reddening of the skin, piloerection, prostration, reduced or lack of response to stimuli, and death) were accompanied by a decrease in body temperature of at least $1^{\circ} \mathrm{C}$. In some experiments, mice were treated with an i.p. injection of the PAF antagonist CV6209 (Biomol International Inc., Plymouth Meeting, PA, USA), given at the dose of $100 \mu \mathrm{g}$ $5 \mathrm{~min}$ before peptide challenge, and/or with the histamine receptor 1 (H1R) antagonist triprolidine (Sigma, St Louis, MO, USA), given i.p. at the dose of $200 \mu \mathrm{g} 30 \mathrm{~min}$ before peptide challenge. Control mice were treated i.p. with PBS. Reagents were diluted in PBS to a final volume of $200 \mu \mathrm{l}$.

\section{Measurement of Serum Ig Responses}

Blood was collected from the tail 6 weeks after the induction of EAE and sera were stored at $-20^{\circ} \mathrm{C}$ until analyzed. Peptide-specific IgG1, IgG2a, and IgE antibodies were measured by enzyme-linked immunosorbent assay (ELISA) as described. ${ }^{5,6,16}$ Briefly, 96-well microtiter plates (Immunol, Thermo Labsystems) were coated overnight at $4^{\circ} \mathrm{C}$ with MOG35-55 diluted in coating buffer $(0.010 \mathrm{mg} / \mathrm{ml})$. Plates were blocked with PBS 10\% FCS for $2 \mathrm{~h}$. Samples were diluted in blocking buffer at 1:100 for IgG1 and IgG2a, and at 1:25 for IgE, and antibody binding was tested by the addition of peroxidase-conjugated monoclonal goat anti-mouse IgG1 or IgG2a (Southern Biotechnology Associates, Birmingham, AL, USA). Enzyme substrate was added and plates were read at $450 \mathrm{~nm}$ on a micro plate reader. Total $\mathrm{IgE}$ was measured by sandwich ELISA (BD PharMingen) following the manufacturer's instructions. ${ }^{16}$ 


\section{Statistical Analysis}

Differences among groups in the time course of body temperature were examined by ANOVA. Differences among groups in the number of mice exhibiting systemic allergic reactions were analyzed by the Fisher's exact test. Two-tailed student's $t$-test was used to compare results between two groups. In all tests, $P<0.05$ was considered statistically significant.

\section{RESULTS}

Expression of Anaphylaxis to MOG35-55 in Mast Cellsor Histidine Decarboxylase-Deficient Mice

$\mathrm{WBB} \mathrm{F}_{1}-K i t^{W / W v}\left(W / W^{v}\right)$ mice, which virtually lack mast cells in all tissues, have been shown to be resistant to the development of IgE-dependent passive systemic anaphylaxis, ${ }^{12,15,20}$ but to be susceptible to passive IgG1-mediated or active anaphylaxis. ${ }^{12,15}$ Challenge with MOG35-55 6 weeks after peptide immunization induced anaphylaxis in both $W / W^{\nu}$ and congenic $\mathrm{Kit}^{+/+}$wild-type mice (Figure 1a and Table 1), indicating that mast cells are not required for the expression of anaphylaxis in this model. Consistent with earlier observations, ${ }^{12,19}$ serum titers of total IgE and, to a lesser extent, of peptide-specific IgG1 antibodies were higher in $W / W^{v}$ vs $\mathrm{Kit}^{+/+}$mice (Figure $1 \mathrm{~b}$ ). We failed to detect antigen-specific IgE with our ELISA method in sera of these mice, as well as in those of all of the other strains used in this study.

$\mathrm{HDC}^{-1-}$ mice, which are profoundly histamine-deficient in all tissues, ${ }^{16,21}$ cannot exhibit hypothermia in association with IgE-dependent passive anaphylaxis. ${ }^{22}$ A paucity of mast cells and abnormalities in mast cell cytoplasmic granules have been described among the phenotypic abnormalities in $\mathrm{HDC}^{-1-}$ mice, ${ }^{21}$ whereas no major differences in basophil number have been observed. We found that $\mathrm{Fc}_{\mathrm{C}} \mathrm{RI}^{+}, \mathrm{B} 220^{-}$ cells (regarded as basophils) represented $2.9 \pm 0.5 \%$ of the total blood cells in $\mathrm{HDC}^{-/-}$mice and $2.8 \pm 0.7 \%$ in $\mathrm{HDC}^{+/+}$mice (data not shown); similarly, Dr Elke Schneider-Necker Hospital, Paris-has found that CD $49^{+}$, Fc\&RI ${ }^{+}$cells (regarded as basophils) represented from 0.6 to $1.2 \%$ of bone marrow cells in $\mathrm{HDC}^{-1-}$ or $\mathrm{HDC}^{+/+}$mice (Elke Schneider, personal communication). Challenge with MOG35-55 induced anaphylaxis in both $\mathrm{HDC}^{-1-}$ and wild-type mice, interestingly with $\mathrm{HDC}^{-1-}$ mice developing a greater drop in body temperature than wild-type mice (Figure 2a and Table 1). As we reported earlier, ${ }^{16}$ total serum IgE titers were significantly increased in $\mathrm{HDC}^{-/-} v s$ wild-type mice, whereas no significant differences were observed in titers of peptide-specific IgG1 (Figure 2b).

The results obtained in mast cell-deficient $W / W^{v}$ mice and histamine-deficient $\mathrm{HDC}^{-1-}$ mice indicate that neither mast cells nor histamine, key players in IgE-dependent anaphylaxis, ${ }^{14}$ are necessary for the development of anaphylaxis to MOG35-55 in mice.

\section{Expression of Anaphylaxis to MOG35-55 in IL-4- Deficient Mice}

IL-4 is required for isotype switching to IgE response and can also promote isotype switching to $\operatorname{IgG} 1 .^{23}$ Active IgEdependent anaphylaxis does not develop in IL-4- or IL-4 receptor-deficient mice. ${ }^{13,14}$ Moreover, the development of IgG1 antibodies with anaphylactic activity requires IL- $4,{ }^{24}$ suggesting that this cytokine is also involved in the development of IgG1-dependent anaphylaxis. As shown in Figure 3a and Table 1, IL-4-deficient mice exhibited little or no anaphylaxis to MOG35-55. As expected in these IL-4deficient mice, which have a general impairment of Th2
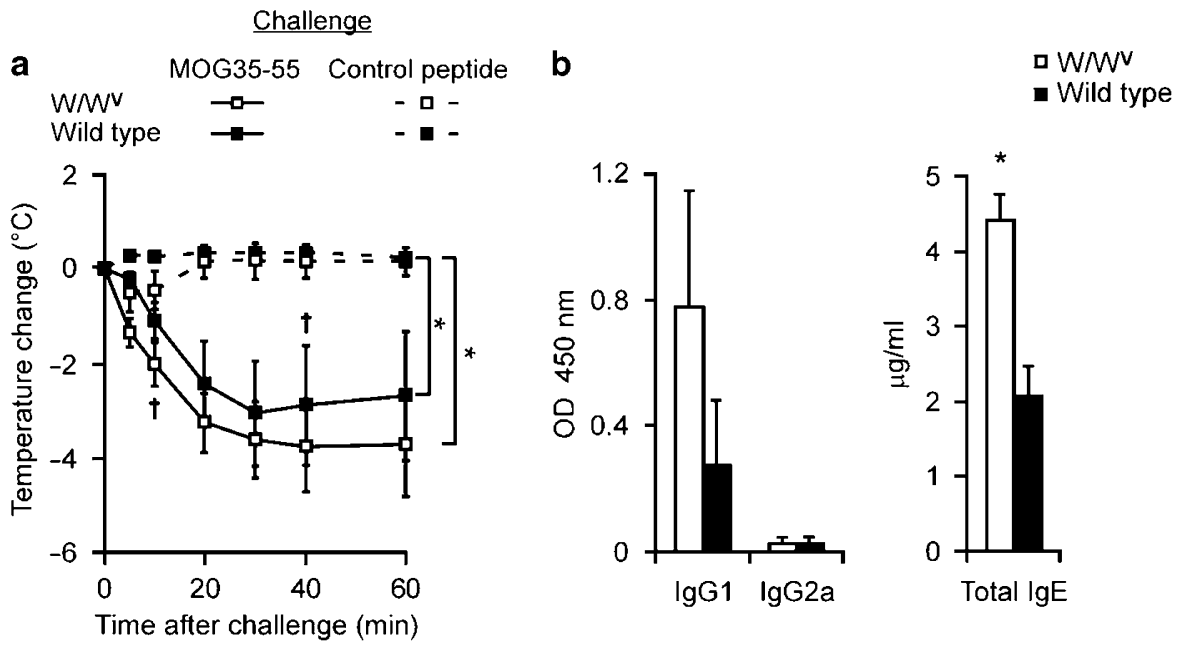

Figure 1 Expression of anaphylaxis to self-MOG35-55 in mast cell-deficient mice. (a) Changes in body temperature in mast cell-deficient WBB6F1-Kit ${ }^{W / W v}$ $\left(W / W^{V}\right)$ and congenic WBB6F1-Kit ${ }^{+/+}\left(\right.$Kit $\left.^{+/+}\right)$mice on i.p. challenge with MOG35-55 or control peptide-1. †One mouse dead from anaphylactic shock at that time point. The exact numbers of challenged mice in the various groups are given in Table $1 .{ }^{*} P<0.001$. (b) MOG35-55-specific IgG1 and IgG2a, and total IgE antibody titers in sera of $W / W^{V}$ and congenic $K_{i t}{ }^{+/+}$mice $(n=6-8$ mice per group $) .{ }^{\star} P<0.005$. 

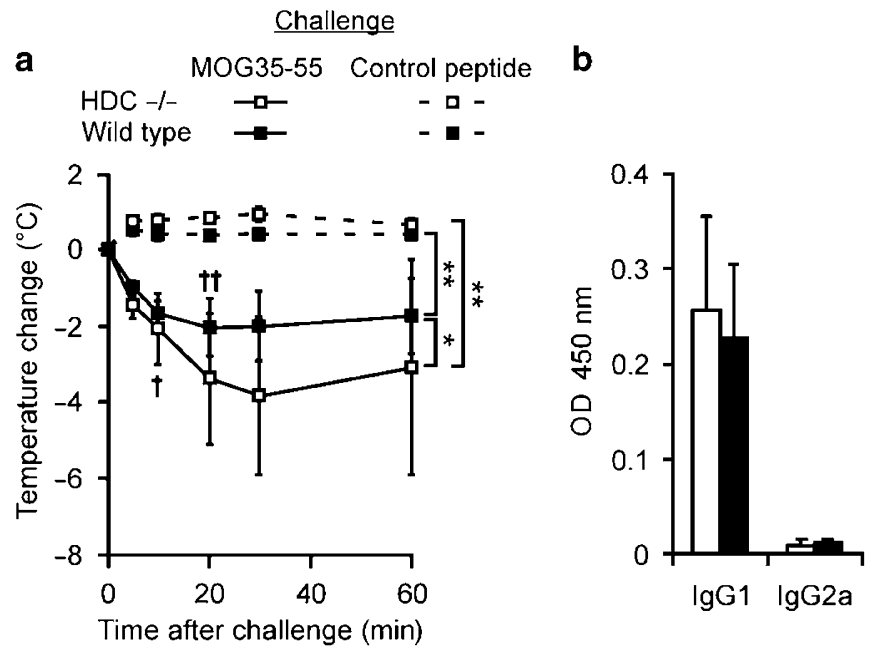

a HDC-1-

- Wild type

Figure 2 Expression of anaphylaxis to self-MOG35-55 in histamine-deficient mice. (a) Changes in body temperature in $\mathrm{C}^{2} \mathrm{BL} / 6-\mathrm{HDC}^{-1-}\left(\mathrm{HDC}^{-1-}\right)$ and control C57BL/6 mice on i.p. challenge with MOG35-55 or control peptide-2. †Three and ††four mice dead from anaphylactic shock at that time point. The exact numbers of challenged mice in the various groups are given in Table 1. ${ }^{*} P<0.05$ and ${ }^{*} P<0.001$. (b) MOG35-55-specific lgG1 and lgG2a, and total lgE antibody titers in sera of $\mathrm{HDC}^{-/-}$and control C57BL/6 mice $\left(n=8-11\right.$ mice per group). ${ }^{*} P<0.05$.
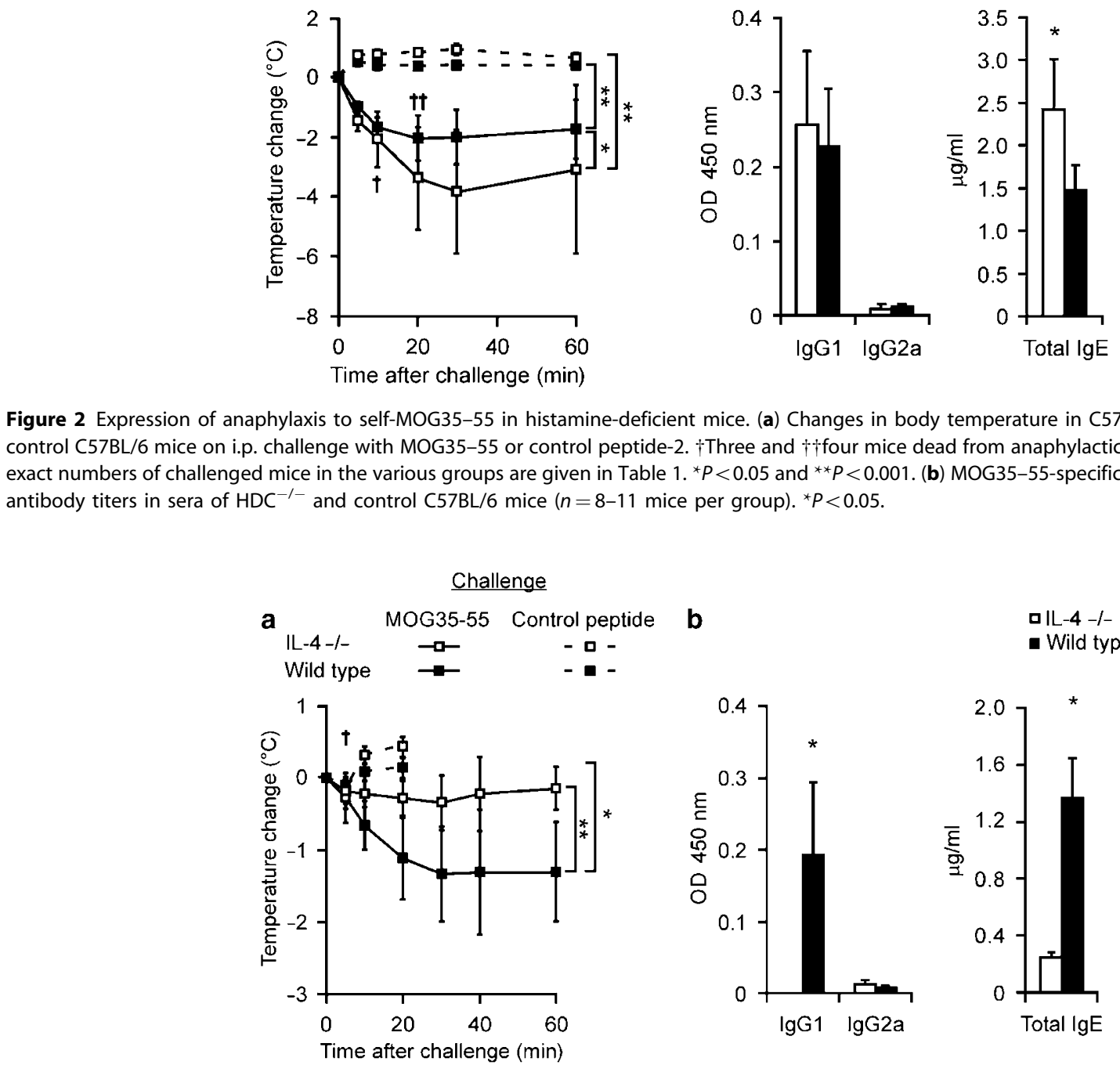

Figure 3 Expression of anaphylaxis to self-MOG35-55 in IL-4-deficient mice. (a) Changes in body temperature in C57BL/6-IL-4 ${ }^{-1-}$ (IL-4 ${ }^{-1-}$ ) and control C57BL/6 mice on i.p. challenge with MOG35-55 or control peptide-1. $†$ One mouse dead at that time point. ${ }^{*} P<0.05$ and ${ }^{* * P<0.005}$. The exact numbers of mice in the various groups are given in Table 1. (b) MOG35-55-specific lgG1 and IgG2a, and total IgE antibody titers in sera of IL-4 ${ }^{-1-}$ and control C57BL/6 mice $\left(n=5-7\right.$ mice per group). ${ }^{\star} P<0.005$.

responses and a significant reduction of IgE and IgG1 antibody production in response to nematode infection, ${ }^{25-27}$ total IgE antibody titers were significantly lower in the sera of IL- $4^{-l-} v s$ wild-type mice, and peptide-specific IgG1 antibodies were below the detection limit (Figure 3b). Accordingly, we hypothesize that the resistance against anaphylaxis to MOG35-55 in these IL-4-knockout mice reflects, at least in part, the absence of a peptide-specific IgG1 (or IgG1 and IgE) response. Indeed, anaphylaxis to MOG35-55 requires antibody binding to $\mathrm{FcR}$, as anaphylaxis to the peptide is abrogated, ${ }^{5}$ or significantly reduced, ${ }^{8}$ in mice that lack the FcR common $\gamma$-chain, and therefore lack FceRI (that binds IgE) and Fc $\gamma$ RIII (that binds IgG1 immune complexes).
However, other mechanisms might also have contributed to resistance against anaphylaxis observed in IL- $4^{-1-}$ mice, such as reduced sensitivity to mediators of anaphylaxis (eg, histamine, PAF, etc) in the absence of this cytokine (reviewed in Finkelman et $a l^{13}$ ) or the absence of antigen binding to basophils, which has recently been described in these knockout mice. $^{28}$

\section{Effects of Blockade of PAF on the Incidence and Severity of Anaphylaxis to MOG35-55}

PAF has been shown to play a major role in IgG-dependent anaphylaxis in the mouse, ${ }^{14}$ and blockade of this mediator can prevent IgG1-mediated passive anaphylaxis in mice. ${ }^{15}$ As 
Table 1 Anaphylaxis in mast cell-, histamine- or IL-4-deficient mice and their controls on challenge with MOG35-55

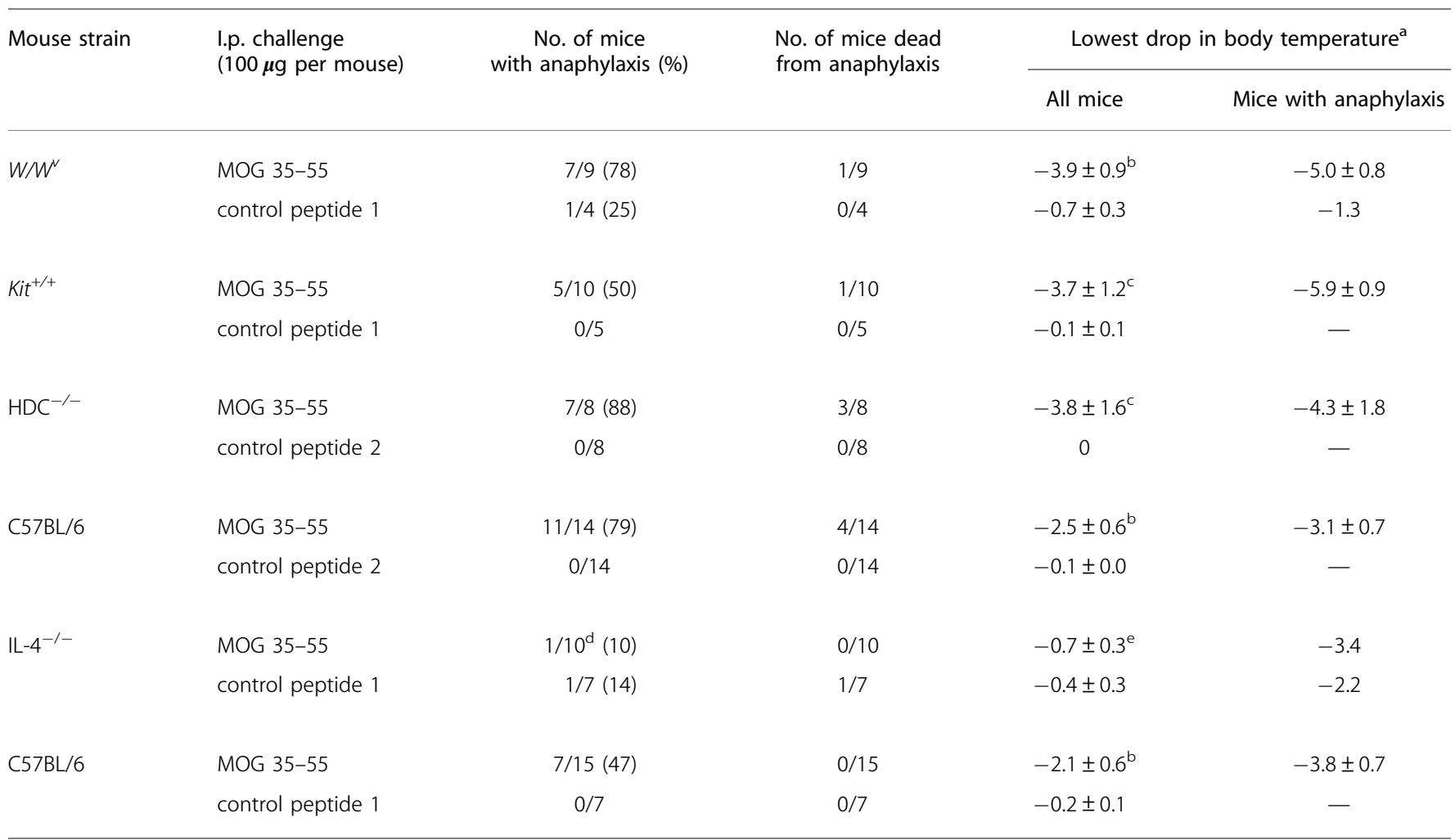

${ }^{\mathrm{a}}$ Data represent mean \pm s.e.m.

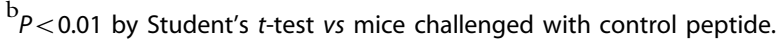

${ }^{\mathrm{c}} P<0.05$ by Student's $t$-test $v s$ mice challenged with control peptide.

$\mathrm{d}_{P<0.05}$ by Fisher's exact test $v$ s corresponding control C57BL/ 6 mice challenged with MOG35-55.

$\mathrm{e}_{P}>0.05$ by Student's $t$-test $v$ s mice challenged with control peptide and $P<0.05$ by Student's $t$-test $v s$ wild-type C57BL/6 mice challenged with MOG35-55.

we observed that anaphylaxis to MOG35-55 was not prevented in mice lacking histamine (Figure $2 \mathrm{a}$ ) or mast cells (Figure 1a), we analyzed the role of PAF in the development of anaphylaxis to this self-peptide. As shown in Table 2, treatment with the PAF antagonist CV6209 slightly reduced the incidence of anaphylaxis to self-MOG35-55 (although this effect was not statistically significant in the number of mice studied), but such treatment did not affect the severity of anaphylaxis, as defined by the mean lowest body temperature developed by mice treated with CV6209 compared with mice treated with vehicle. Treatment with H1R receptor antagonist triprolidine was not effective in preventing anaphylaxis to self-MOG35-55, confirming the results obtained in $\mathrm{HDC}^{-1-}$ mice, whereas treatment with CV6209 and triprolidine in combination was slightly more effective than treatment with CV6209 alone in reducing the incidence of anaphylaxis to this peptide (Table 2). Although the effects detected did not achieve statistical significance, these results suggest that PAF plays a role in anaphylaxis to MOG35-55, but is not the only mediator involved.

We also evaluated the role of PAF in another model of anaphylaxis to MOG35-55, elicited in C57BL/6 mice that were immunized with this peptide in CFA, but without B. pertussis toxin (PTX) used as an adjuvant. As reported earlier, ${ }^{6}$ under this protocol of immunization, mice developed anaphylaxis with higher doses of antigen as compared with mice that had received PTX at the time of peptide immunization $(500 v s 100 \mu \mathrm{g})$. Also, compared with mice that received PTX at the time of immunization, these mice had significantly lower titers of total IgE in their serum (total IgE levels were $204.2 \pm 13 \mathrm{ng} / \mathrm{ml}$ in mice that did not receive PTX vs $1.0 \pm 0.25 \mu \mathrm{g} / \mathrm{ml}$ in mice that received PTX; $P=0.007)$ and higher antigen-specific IgG1 titers (OD was $1.137 \pm 0.191$ in mice that did not receive PTX vs $0.724 \pm 0.074$ in mice that received PTX; $P=0.037)$. In mice subjected to this immunization protocol (Table 3), treatment with the PAF antagonist was more effective in reducing the severity of anaphylaxis to MOG35-55 than in our standard protocol. Anaphylaxis occurred in 3 of 10 mice treated with CV6209 vs 6 of 10 mice treated with vehicle $(P=0.353)$, and the mean maximum drop in body temperature was $0.8 \pm 0.4^{\circ}$ in mice treated with CV6209 vs $2.6 \pm 0.7^{\circ}$ in mice treated with vehicle $(P=0.037)$. Moreover, in this immunization protocol, treatment with both CV6209 and triprolidine was more 
Table 2 Anaphylaxis in wild-type C57BI/6 mice treated with a PAF antagonist and/or an H1R antagonist before peptide challenge (in mice immunized to MOG35-55 with Bordetella pertussis toxin)

\begin{tabular}{lccc}
\hline Treatment & $\begin{array}{c}\text { No. of mice with } \\
\text { anaphylaxis (\%) }\end{array}$ & $\begin{array}{c}\text { No. of mice dead } \\
\text { from anaphylaxis }\end{array}$ & All mice \\
\cline { 3 - 4 } & $3 / 8(37)$ & $1 / 8$ & $-2.0 \pm 1.0$ \\
CV6209 & $4 / 8(50)$ & $0 / 8$ & $-2.2 \pm 1.0$ \\
Triprolidine & $2 / 8(25)$ & $1 / 8$ & $-1.3 \pm 0.7$ \\
CV6209+Triprolidine & $6 / 10(60)$ & $2 / 10$ & $-2.0 \pm 0.8$ \\
Vehicle & & & $-4.9 \pm 1.5$ \\
\hline
\end{tabular}

${ }^{\mathrm{a}}$ Data represent mean \pm s.e.m.

Table 3 Anaphylactic shock in wild-type C57BI/6 mice treated with a PAF antagonist and/or an H1R antagonist before peptide challenge (in mice immunized to MOG35-55 without Bordetella pertussis toxin)

\begin{tabular}{lccc}
\hline Treatment & $\begin{array}{c}\text { No. of mice with } \\
\text { anaphylaxis (\%) }\end{array}$ & $\begin{array}{c}\text { No. of mice dead } \\
\text { from anaphylaxis }\end{array}$ & All mice \\
\cline { 3 - 4 } & $3 / 10(30)$ & $0 / 10$ & $-0.8 \pm 0.4^{\mathrm{b}}$ \\
CV6209 & $4 / 10(40)$ & $0 / 10$ & $-1.5 \pm 0.6$ \\
Triprolidine & $1 / 10(10)^{\mathrm{c}}$ & $0 / 10$ & $-0.3 \pm 0.2^{\mathrm{b}}$ \\
CV6209+Triprolidine & $6 / 10(60)$ & $0 / 10$ & $-2.6 \pm 0.7$ \\
Vehicle & & & $-3.4 \pm 1.0$
\end{tabular}

\footnotetext{
${ }^{\mathrm{a}}$ Data represent mean \pm s.e.m.

${ }^{\mathrm{b}} P<0.05$ by Student's $t$-test $v s$ vehicle-treated mice.

${ }^{\mathrm{c}} P<0.05$ by Fisher's exact test $v s$ vehicle-treated mice.
}

effective in preventing anaphylaxis than was treatment with CV6209 or with triprolidine alone (Table 3). Anaphylaxis occurred in 1 of 10 mice treated with CV6209 and triprolidine $v s 6$ of 10 mice treated with vehicle $(P=0.028)$; the mean maximum body temperature drop was $0.3 \pm 0.2^{\circ}$ in mice treated with CV6209 and triprolidine vs $2.6 \pm 0.7$ in mice treated with vehicle $(P=0.010)$. Taken together, our data suggest that PAF may have a more significant role in this model of anaphylaxis to self-MOG35-55 (Table 3) compared with the model in which PTX is used (Table 2). However, in both models, our data suggest that mediators other than PAF are also involved. Indeed, our results with triprolidine are consistent with the possibility that even though it is not essential for the responses, histamine may contribute to some of the changes seen in association with anaphylaxis to MOG35-55, especially in the model in which immunization was elicited with PTX.

\section{DISCUSSION}

Our results indicate that anaphylaxis to self-MOG35-55 can be induced in mice in the absence of mast cells or histamine, but does require IL-4. The findings in this study are consistent with the possibility that the pathway of anaphylaxis to self-MOG35-55 involves IgG1, Fc $\gamma$ RIII, macrophages and/or basophils, and PAF. ${ }^{5}$ However, the PAF antagonist CV6209 was not fully effective in abrogating the changes in body temperature associated with anaphylaxis to MOG35-55 in either of the two models tested, indicating that other mediators are also probably involved. Prior work by us ${ }^{5}$ and others ${ }^{8}$ found that anaphylaxis to self in this model was not eliminated in mice lacking the $\alpha$ chain of Fc $\gamma$ RIII $\left(\right.$ Fc $\gamma$ RIII $\alpha$ chain $\left.^{-1-}\right)$. Taken together with the results presented here, this finding suggests that, if IgG1 antibodies indeed contribute importantly to anaphylaxis in this model, such IgG1 antibodies may be functioning through mechanisms other than binding as immune complexes to Fc $\gamma$ RIII.

However, our results do not rule out possible contributions in this model of anaphylaxis of an alternative pathway that involves IgE but that requires neither mast cells nor histamine. Like mast cells, basophils express FcєRI and Fc $\gamma$ RIII, and therefore might be activated in this model by either IgE- or IgG1-dependent mechanisms. Basophils are present in the mast cell-deficient $W / W^{\nu}$ mice that we used in our experiments, although in some settings in somewhat lower numbers than in the corresponding wild-type mice, as well as in mast cell-deficient $W^{-S h} / W^{-S h}$ mice. ${ }^{29-32}$ Indeed, 
depletion of basophils in $W^{S h} / W^{S h}$ mice in vivo with a monoclonal antibody suppressed IgG1-mediated passive systemic anaphylaxis, revealing an important role for basophils in that model of IgG1-mediated anaphylaxis. ${ }^{15}$ Thus, although we cannot exclude an involvement of other cells, such as macrophages, in the models of MOG35-55-induced anaphylaxis that we tested, basophils activated by $\operatorname{IgE}$ (and/or IgG1) might represent important effector cells in anaphylaxis to self-MOG, especially in mast cell-deficient mice. In future studies, selective depletion of basophils and/or macrophages in vivo might help to define the role of these cells in anaphylaxis to self-MOG35-55.

Blockade of PAF with the antagonist CV6209, which effectively blocked IgG1-dependent passive systemic anaphylaxis, ${ }^{15}$ only partially reduced the incidence of active systemic anaphylaxis to MOG35-55 in the main model of immunization to MOG35-55 that was used in our study, and this effect did not achieve statistical significance. However, CV6209 seemed to be more effective in substantially reducing the severity of anaphylaxis to this self-peptide in a model that omitted PTX as an adjuvant at the time of immunization. These results suggest that PAF plays a role in anaphylaxis to this self-peptide in the two immunization models examined, but is unlikely to be the only mediator involved. Our results also indicated that a combination of both CV6209 and the $\mathrm{H} 1 \mathrm{R}$ antagonist triprolidine was more effective in inhibiting anaphylaxis than was treatment with CV6209 or with triprolidine alone, especially in the immunization model that omitted PTX as an adjuvant (Table 3). These findings are consistent with those reported in a model of self-anaphylaxis induced in a non-obese diabetic (NOD) mouse model of human diabetes mellitus, in which only the treatment with both PAF antagonist and H1R antagonist in combination, but not with either of them used alone, was effective in preventing anaphylaxis to self-insulin peptides. ${ }^{33}$ One way to interpret all of our data is that even though anaphylaxis to MOG35-55 in mice does not require either mast cells or histamine, and PAF is one of the mediators that contribute to the pathology in this setting, histamine (or another mediator whose effects may be reduced by treatment with triprolidine) also can contribute to the pathology.

The data presented here were derived entirely from studies in mouse models, and their implications for the clinical management of MS and other autoimmune disorders remain to be ascertained. Even though $\operatorname{IgE}$ is thought to be the main (or only) Ig isotype that contributes significantly to anaphylactic and allergic responses in humans (reviewed in Finkelman $e \mathrm{al}^{13}$ ), anaphylaxis has been reported in people in whom there was no evidence of antigen-specific IgE antibodies or mast cell degranulation (reviewed in Finkelman et $a l^{13}$ ). Some of such cases might reflect the existence of IgGdependent, but IgE-independent, pathways of anaphylaxis. It is worth mentioning here that MS patients who developed allergic reactions to NB5788, which usually occurred in those receiving the highest doses of this APL, presented with elevated titers of peptide-specific IgG1 antibodies, but not of peptide-specific IgE antibody levels. ${ }^{9}$ Also, despite the frequent appearance of allergic reactions in glatiramer acetate-treated patients, glatiramer acetate-specific IgE was detected only in one patient. ${ }^{34}$ It is possible that the allergic reactions to peptide therapies occurring in such individuals might have components of IgG-, but not IgE-, dependent pathways of anaphylaxis. However, the relationship of these clinical findings to the data reported herein from our studies in mice remains to be ascertained. Indeed, in humans, the antibody isotype thought to be most similar to IgG1 in mice is not IgG1, but IgG4. ${ }^{35,36}$

In conclusion, we have shown here that anaphylaxis to selfMOG35-55 in mice can occur in the absence of mast cells and histamine, key elements of the classical IgE-, mast cell-, and histamine-dependent pathway of anaphylaxis. Our pharmacological data suggest that PAF can contribute to the pathology associated with anaphylaxis to MOG35-55, especially in a model in which mice are immunized to the peptide without the use of PTX as an adjuvant, but that other mediators are likely also to be involved. Although one must always be cautious in extrapolating the results of mouse studies to humans, our data raise the possibility that drugs that block effector mechanisms of the classical IgE-dependent pathway of anaphylaxis, such as anti-histamines or inhibitors of mast cell degranulation, might be ineffective in preventing certain forms of peptide-induced anaphylaxis in human subjects.

\section{ACKNOWLEDGEMENTS}

We thank Dennis Mitchell for technical help and Renato Longhi for providing the peptide used in this study. This work was funded by grants from the National MS Society-New York, CARIPLO foundation and 'Ricerca Finalizzata-Ministero della Salute' (to RP).

\section{DISCLOSURE}

The authors declare no conflicts of interest.

1. Steinman L. Optic neuritis, a new variant of experimental encephalomyelitis, a durable model for all seasons, now in its seventieth year. J Exp Med 2003;197:1065-1071.

2. Fontoura P, Garren H, Steinman L. Antigen-specific therapies in multiple sclerosis: going beyond proteins and peptides. Int Rev Immunol 2005;24:415-446.

3. McDevitt H. Specific antigen vaccination to treat autoimmune disease. Proc Natl Acad Sci USA 2004;101(Suppl 2):14627-14630.

4. Lichtenegger FS, Kuerten S, Faas S, et al. Dissociation of experimental allergic encephalomyelitis protective effect and allergic side reactions in tolerization with neuroantigen. J Immunol 2007;178:4749-4756.

5. Pedotti R, DeVoss JJ, Youssef S, et al. Multiple elements of the allergic arm of the immune response modulate autoimmune demyelination. Proc Natl Acad Sci USA 2003;100:1867-1872.

6. Pedotti R, Mitchell D, Wedemeyer J, et al. An unexpected version of horror autotoxicus: anaphylactic shock to a self-peptide. Nat Immunol 2001;2:216-222.

7. Scabeni S, Lapilla M, Musio S, et al. CD4+CD25+ regulatory T cells specific for a thymus-expressed antigen prevent the development of anaphylaxis to self. J Immunol 2008;180:4433-4440.

8. Smith CE, Eagar TN, Strominger JL, et al. Differential induction of IgE-mediated anaphylaxis after soluble vs cell-bound tolerogenic peptide therapy of autoimmune encephalomyelitis. Proc Natl Acad Sci USA 2005;102:9595-9600. 
9. Kappos $\mathrm{L}$, Comi $\mathrm{G}$, Panitch $\mathrm{H}$, et al. Induction of a nonencephalitogenic type $2 \mathrm{~T}$ helper-cell autoimmune response in multiple sclerosis after administration of an altered peptide ligand in a placebo-controlled, randomized phase II trial. Nat Med 2000;6:1176-1182.

10. Aharoni R, Teitelbaum $D$, Arnon $R$, et al. Copolymer 1 acts against the immunodominant epitope $82-100$ of myelin basic protein by $\mathrm{T}$ cell receptor antagonism in addition to major histocompatibility complex blocking. Proc Natl Acad Sci USA 1999;96:634-639.

11. Kawakami T, Galli SJ. Regulation of mast-cell and basophil function and survival by IgE. Nat Rev Immunol 2002;2:773-786.

12. Miyajima I, Dombrowicz D, Martin TR, et al. Systemic anaphylaxis in the mouse can be mediated largely through $\operatorname{lgG} 1$ and FcyRIII. Assessment of the cardiopulmonary changes, mast cell degranulation, and death associated with active or IgE- or IgG1-dependent passive anaphylaxis. $J$ Clin Invest 1997;99:901-914.

13. Finkelman FD, Rothenberg ME, Brandt EB, et al. Molecular mechanisms of anaphylaxis: lessons from studies with murine models. J Allergy Clin Immunol 2005;115:449-457; quiz 458.

14. Strait RT, Morris SC, Yang M, et al. Pathways of anaphylaxis in the mouse. J Allergy Clin Immunol 2002;109:658-668.

15. Tsujimura $\mathrm{Y}$, Obata $\mathrm{K}$, Mukai $\mathrm{K}$, et al. Basophils play a pivotal role in immunoglobulin-g-mediated but not immunoglobulin-e-mediated systemic anaphylaxis. Immunity 2008;28:581-589.

16. Musio S, Gallo B, Scabeni S, et al. A key regulatory role for histamine in experimental autoimmune encephalomyelitis: disease exacerbation in histidine decarboxylase-deficient mice. J Immunol 2006;176: $17-26$.

17. Bettelli E, Das MP, Howard ED, et al. IL-10 is critical in the regulation of autoimmune encephalomyelitis as demonstrated by studies of IL-10- and IL-4-deficient and transgenic mice. J Immunol 1998;161:3299-3306.

18. Liblau R, Steinman L, Brocke $S$. Experimental autoimmune encephalomyelitis in IL-4-deficient mice. Int Immunol 1997;9:799-803.

19. Secor VH, Secor WE, Gutekunst CA, et al. Mast cells are essential for early onset and severe disease in a murine model of multiple sclerosis. J Exp Med 2000;191:813-822.

20. Takeishi T, Martin TR, Katona IM, et al. Differences in the expression of the cardiopulmonary alterations associated with anti-immunoglobulin E-induced or active anaphylaxis in mast cell-deficient and normal mice. Mast cells are not required for the cardiopulmonary changes associated with certain fatal anaphylactic responses. J Clin Invest 1991;88:598-608.
21. Ohtsu H, Tanaka S, Terui T, et al. Mice lacking histidine decarboxylase exhibit abnormal mast cells. FEBS Lett 2001;502:53-56.

22. Makabe-Kobayashi Y, Hori Y, Adachi T, et al. The control effect of histamine on body temperature and respiratory function in IgEdependent systemic anaphylaxis. J Allergy Clin Immunol 2002;110:298-303.

23. Stevens TL, Bossie A, Sanders VM, et al. Regulation of antibody isotype secretion by subsets of antigen-specific helper T cells. Nature 1988;334:255-258.

24. Faquim-Mauro EL, Coffman RL, Abrahamsohn IA, et al. Cutting edge: mouse IgG1 antibodies comprise two functionally distinct types that are differentially regulated by IL-4 and IL-12. J Immunol 1999;163:3572-3576.

25. Kopf M, Le Gros G, Bachmann M, et al. Disruption of the murine IL-4 gene blocks Th2 cytokine responses. Nature 1993;362:245-248.

26. Kuhn R, Rajewsky K, Muller W. Generation and analysis of interleukin-4 deficient mice. Science 1991;254:707-710.

27. McKenzie GJ, Fallon PG, Emson CL, et al. Simultaneous disruption of interleukin (IL)-4 and IL-13 defines individual roles in T helper cell type 2-mediated responses. J Exp Med 1999;189:1565-1572.

28. Denzel A, Maus UA, Rodriguez Gomez M, et al. Basophils enhance immunological memory responses. Nat Immunol 2008;9:733-742.

29. Grimbaldeston MA, Chen CC, Piliponsky AM, et al. Mast cell-deficient W-sash c-kit mutant Kit W-sh/W-sh mice as a model for investigating mast cell biology in vivo. Am J Pathol 2005;167:835-848.

30. Lantz CS, Boesiger J, Song $\mathrm{CH}$, et al. Role for interleukin-3 in mast-cell and basophil development and in immunity to parasites. Nature 1998;392:90-93.

31. Mukai K, Matsuoka K, Taya C, et al. Basophils play a critical role in the development of IgE-mediated chronic allergic inflammation independently of T cells and mast cells. Immunity 2005;23:191-202.

32. Obata K, Mukai K, Tsujimura Y, et al. Basophils are essential initiators of a novel type of chronic allergic inflammation. Blood 2007;110:913-920.

33. Liu $\mathrm{E}$, Moriyama $\mathrm{H}$, Abiru N, et al. Anti-peptide autoantibodies and fatal anaphylaxis in NOD mice in response to insulin self-peptides B:9-23 and B:13-23. J Clin Invest 2002;110:1021-1027.

34. Rauschka $H$, Farina $C$, Sator $P$, et al. Severe anaphylactic reaction to glatiramer acetate with specific IgE. Neurology 2005;64:1481-1482.

35. Aalberse RC, van der Gaag R, van Leeuwen J. Serologic aspects of IgG4 antibodies. I. Prolonged immunization results in an IgG4-restricted response. J Immunol 1983;130:722-726.

36. Larche $M$, Akdis CA, Valenta R. Immunological mechanisms of allergenspecific immunotherapy. Nat Rev Immunol 2006;6:761-771. 